\section{Overcoming the problems of solid state drug formulations with ionic liquids}

\author{
We were guided by the fact that pure liquid salt forms ... from parent active \\ pharmaceutical ingredients can possibly overcome the deficiencies of solid active \\ pharmaceutical ingredients and, thus, might be used as alternative, versatile tools in \\ the pharmaceutical industry.
}

\begin{abstract}
Keywords: active pharmaceutical ingredients $\bullet$ drug delivery $\bullet$ ionic liquid $\bullet$ liquid salt - pharmaceutical industry
\end{abstract}

\section{When opinions crystallize, is progress lost?}

Currently, the pharmaceutical industry relies almost entirely on solid active pharmaceutical ingredients (APIs), which exist in various forms including crystalline and amorphous materials, salts, hydrates and other solvates, co-crystals, and so on, and the various polymorphs (or pseudo-polymorphs) of each of these $[1,2]$. In order to exclude problems associated with polymorphism, the International Conference for Harmonization (ICH) requires a thorough study of each new API [3]. However, beyond the well-known issues of polymorphism, other aspects of the solid state such as bulk properties, powder morphology, particle size, and physicochemical and solution properties, significantly influence the performance characteristics of APIs, and in particular their pharmacokinetics [4]. Improving drug solubility and bioavailability still remains vital challenges in drug development, and low solubility often complicates the delivery of both new and currently marketed drugs. Seeking ways to improve the bioavailability of drugs, pharmaceutical companies are designing novel drug-delivery systems, making dispersions, drug complexes (e.g., with cyclodextrin), dendrimers, nanosuspensions, co-crystals, using co-solvents, and adjusting $\mathrm{pH}$, to name just a few techniques, all directed toward improving the solid state of APIs or making the solids more tractable for delivery or use [5].

Why does pharma insist on solid, preferably crystalline APIs, rather than trying to take advantage of easily accessible pure liquid states for some APIs? First and foremost, there are already established US FDA guidelines regarding current good manufacturing practices for solid APIs (manufacturing, performance testing, monitoring, process validation, release and stability testing, packing, storage) [6]. Another factor is built in standardized operating equipment at various scales, which allows manufacturing capabilities to be matched to almost any solid processing requirements, and thus can be used for production of numerous APIs. Perhaps a third factor is the industry's fear of failure. In other words, the pharmaceutical industry adheres to tried and tested methods and is reluctant to change, afraid of the unknown (and unknown costs) and driven by habit, convinced that what worked in the past will work in the future.

Nonetheless, the industry is still successful, which raises the question, is innovation and change really necessary beyond the wellproven methodologies at work today? Why not stick with crystalline solids, or at least solids in general? Perhaps one reason might be solubility-dependent bioavailability, which will depend on the API phase (crystalline vs amorphous; salt vs free-form) [7] where absorption of an API that was a liquid will be higher than that of solid because solids need a 'dissolution phase' for the absorption process to occur [8]. Not only is absorption of a liquid drug higher, but liquids may also be designed for any route of absorption - oral, parenteral (injections), rectal, topical, or as ophthalmic liquids, not to mention that liquids are mandatory anyway for certain target markets such as infants, babies or the elderly.

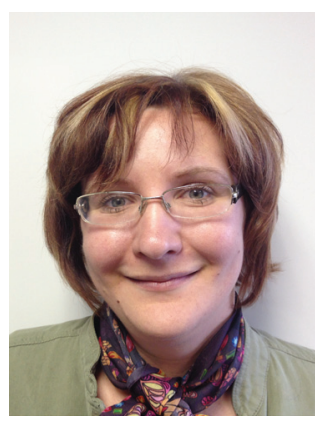

Julia L Shamshina Center for Green Manufacturing \& Department of Chemistry, The University of Alabama, Tuscaloosa, AL 35487, USA and

525 Solutions, Inc., 720 2nd Street, Tuscaloosa, AL 35401, USA

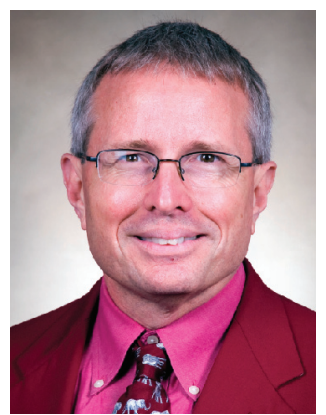

Robin D Rogers

Author for correspondence: Center for Green Manufacturing \& Department of Chemistry, The University of Alabama, Tuscaloosa, AL 35487, USA rdrogers@ua.edu 
Salt formation is traditionally used by pharma to alter the drug's pharmacokinetics when using the same active ingredient $[9,10]$. Through the use of acidic or basic compounds that neutralize the parent drug (base or acid, respectively), pharmaceutical companies generate salts that differ in drug solubility, dissolution rates, absorption, pharmacokinetics, drug action, and so on [11]. Altering the chemical properties of a pharmaceutical active such as $\log P$ (an estimate of a compound's overall lipophilicity) through salt formation will influence the behavior of the parent drug's absorption and distribution within the body [12]; for example, different salts of ibuprofen have different absorption rates [13]. However, such salt formation is focused on the production of a solid salt form, which is preferably crystalline, where all of the disadvantages of solids remain. This bias against liquids has made it difficult at times to gain traction for advances that may provide new treatment options or overcome many problems associated with the solid state by making APIs as pure liquids.

We have recently taken known and marketed active substances and prepared salts of them in liquid form (at or below body temperatures) [14,15]. We were guided by the fact that pure liquid salt forms (which we call ionic liquids [ILs]) from parent APIs can possibly overcome the deficiencies of solid APIs and, thus, might be used as alternative, versatile tools in the pharmaceutical industry. Recent developments in this area have shown that APIs are often readily converted into the liquid salt form and this can have a direct effect on solubilities and dissolution rates. For example, we have shown that liquid salt forms of acyclovir can result in 70-500-fold increased solubility.

As our understanding of the area has grown, we have developed new tools [16] for relatively easy modification of the melting point of a drug, which include:

- API-ILs themselves;

- 'Liquid co-crystals';

- Formation of oligomeric ions that enable liquefaction of solid ILs by changing the stoichiometry or complexity of the ions;

- Combining an IL strategy with the prodrug strategy;

- Design of 'edible' IL excipients for dissolving and delivering 'hard-to-dissolve' APIs;

- Creating ILs that match the structural requirements needed to solubilize poorly soluble APIs.

We, alongside others, are creating more tools in our search for control over the liquid salt state of matter, with the belief that API-ILs could provide new biologically active combinations and new delivery options, providing new drugs and offering improved performance. This could allow pharmaceutical manufacturers greater latitude in the development of compounds that might have otherwise failed.

Perhaps some baby steps in the fully fledged embracing of liquid salts are being taken. For example, a Japanese R\&D firm, MedRx, has developed several transdermal IL-based systems (e.g., Etodolac ${ }^{\circledR}$ and ETOREAT $^{\circledR}$ analgetic adhesive patches) through a technology they call ionic liquid transdermal systems $\left(\right.$ ILTS $\left.^{\circledR}\right)$, which converts poorly soluble (thus, poorly absorbable) drugs into highly soluble and absorbable transdermal formulations. A Phase III study of ETOREAT is currently ongoing in the USA, and MRX-7LAT for topical pain relief modification and MRX-1OXT for central analgesic are in preclinical stages [17].

\footnotetext{
"The ability to make liquid salt forms of active pharmaceutical ingredients should be used as a tool early in drug discovery and development to ensure that every new active entity has been exhaustively investigated.
}

We understand that while the IL platform can create many possibilities for the preparation of liquid drugs, it is too early for implementation. The pharmaceutical industry has to deliberately study the field of API-ILs, and increased funding and research efforts are essential for studies of solution properties, pharmacokinetics, preclinical trials, development of analytics, and so on. There is also still a need for FDA guidance. For example, the FDA has only recently proposed grouping multicomponent APIs into either salts, solvates or co-crystals, with solvates and co-crystals being considered formulations rather than new compounds [18]. Solid state scientists have protested that this classification oversimplifies the generally accepted salt co-crystal continuum $[1,19]$. There is reason to suspect that the many possible forms of fully and partially ionized species in a multicomponent API will result in structures that have neither strictly salt-like or co-crystalline properties [20]. Liquid APIs, and the possibility of ranges in terms of fully ionic, nonstoichiometric compounds, hydrogen-bonded complexes, oligomers, and so on, each possibly with its own properties and structure, will undoubtedly further complicate the regulatory issues. As a consequence of such diversity, it may often be difficult to decide whether API-ILs are new drugs or new formulations.

No matter how big the goal is, the key seems to be consistency and determination to achieve it. As 
the renowned advertiser David Ogilvy once said: "Encourage innovation. Change is our life blood, stagnation is our death knell". We do understand that there are risks associated with development of any new drug form, but the potential benefits are often worth the risk. The pharmaceutical industry should relax its mindset that crystalline APIs are the gold standard. Yes, certainly there are many advantages to the crystalline state of matter, but there are many disadvantages as well. The ability to make liquid salt forms of APIs should be used as a tool early in drug discovery and development to ensure that every new active entity has been exhaustively investigated. Failure is often not an option, and when failure is tied to not trying, it is even worse. We would like to encourage the pharmaceutical industry to dedicate time and research to the investigation of API-ILs.

\section{References}

1 Aitipamula S, Banerjee R, Bansal A et al. Polymorphs, salts, and cocrystals: what's in a name? Cryst. Growth Des. 12(5), 2147-2152 (2012).

2 Newman AW, Stahly GP. Form Selection of Pharmaceutical Compounds. In: Handbook of Pharmaceutical Analysis. Ohannesian L, Streeter A (Eds). Marcel Dekker, NY, USA, $1-57$ (2002).

3 International Conference on Harmonization of Technical Requirements for Registration of Pharmaceuticals for Human Use. ICH Harmonized Tripartite Guideline Specifications: Test Procedures and Acceptance Criteria for New Drug Substances and New Drug Products. Chemical Substances Q6A.

www.ich.org/fileadmin/Public_Web_Site/ICH_Products/ Guidelines/Quality/Q6A/Step4/Q6Astep4.pdf

4 Florence AT, Attwood D. Physicochemical Principles of Pharmacy (5th Edition). Pharmaceutical Press, Royal Pharmaceutical Society of Great Britain, London, UK (2011).

5 Hart ML, Do DP, Ansari RA et al. Brief overview of various approaches to enhance drug solubility. J. Develop. Drugs 2(3), 115-121 (2013).

6 Guidance for Industry Q7A: Good Manufacturing Practice Guidance for Active Pharmaceutical Ingredients. US Department of Health and Human Services, Food and Drug Administration, Center for Drug Evaluation and Research (CDER), Center for Biologics Evaluation and Research (CBER), August 2001, ICH.

www.fda.gov/downloads/regulatoryinformation/guidances/ ucm129098.pdf

7 Kesisoglou F, Wu Y. Understanding the effect of API properties on bioavailability through absorption modeling. AAPS J. 11(1), 31-52 (2009).

8 Yellela SRK. Pharmaceutical technologies for enhancing oral bioavailability of poorly soluble drugs. J. Bioequiv. Availab. 2(2), 28-36(2010).

\section{Disclaimer}

This editorial describes solely the opinions and observations of the authors as scientists in the field of active pharmaceutical ingredient - ionic liquids.

\section{Financial \& competing interests disclosure}

RD Rogers has partial ownership of 525 Solutions and is a named inventor on related patent applications. JL Shamshina is a part-time employee of 525 Solutions. The University of Alabama maintains approved Conflict of Interest Management Plans. The authors have no other relevant affiliations or financial involvement with any organization or entity with a financial interest in or financial conflict with the subject matter or materials discussed in the manuscript apart from those disclosed.

No writing assistance was utilized in the production of this manuscript.

9 Gould PL. Salt selection for basic drugs. Int. J. Pharm. 33, 201-17 (1986).

10 Serajuddin ATM, Pudipeddi M. Salt selection strategies. In: Handbook of Pharmaceutical Salts: Properties, Selection, and Use. Stahl PH, Wermuth CG (Eds). Wiley-VCH, Weinheim, Germany, 135-160 (2002).

11 Serajuddin ATM. Salt formation to improve drug solubility. Adv. Drug Deliv. Rev. 59(7), 603-616 (2007).

12 Leo A, Hansch C, Elkins D et al. Partition coefficients and their uses. Chem. Rev. 71(6), 525-616 (1971).

13 Sarveiya V, Templeton JF, Benson HAE et al. Ion-pairs of ibuprofen: increased membrane diffusion. J. Pharm. Pharmacol. 56(6), 717-724 (2004).

14 Hough WL, Rogers RD. Ionic liquids then and now: from solvents to materials to active pharmaceutical ingredients. Bull. Chem. Soc. Jpn 80 (12), 2262-2269 (2007).

15 Rogers RD, Daly DT, Swatloski RP et al. US8232265 (2012); WO 2007044693 A3 (2007); MX 301158 (2012).

16 Shamshina JL, Barber PS, Rogers RD et al. Ionic liquids in drug delivery. Expert Opin. Drug Deliv. 10 (10), 1367-1381 (2013).

17 MedRX news release. MEDRx, Co., Ltd to present at BioEurope Spring, 10-12 March, 2014, Turin, Italy. www.medrx.co.jp/pdf/eng_140217_present_at_BioEurope_ in_Turin_Italy.pdf

18 US Food and Drug Administration. Guidance for Industry: Regulatory Classification of Pharmaceutical Co-Crystals. Silver Spring, MD, USA (2011).

19 Aakeröy CB, Fasulo ME, Desper J et al. Salt or co-crystal: does it really matter? Mol. Pharma. 4, 317-322 (2007).

20 Kelley SP, Narita A, Holbrey JD et al. Understanding the effects of ionicity in salts, solvates, co-crystals, ionic co-crystals, and ionic liquids, rather than nomenclature, is critical to understanding their behavior. Cryst. Growth Des. 13(3), 965-975 (2013). 